\title{
Editorial: BRJB 36(4)
}

\author{
Antonio Salatino
}

Published online: 11 December 2013

(C) Botanical Society of Sao Paulo 2013

As usual, BRJB presents, in this issue, papers covering a wide diversity of topics in botany. There are two papers dealing with algae, both examining the variation of algal communities. The paper by Pereira et al. reports variation, dependent on nutrient availability, on the periphytic algal community along the length of a river. The other paper about algae deals with the functional diversity and adaptive strategies of planktonic and periphytic organisms (Dunk et al.). Mühlsteinová \& Hauer studied the diversity of cyanobacteria in the aeroterrestrial environment in a region of Costa Rica. The present issue contains also papers on diverse areas of research of angiosperm biology. A very rare species of Thismia (T. singeri, Thismiaceae) is recorded for the first time in Brazil; Voloschen et al. provide a broad description of the species, pointing out features enabling the distinction between $T$. singer and $T$. hyalina. The paper by Shabir et al. is an account of the complete chronological development (from seedling to senescence) of the alpine herb Inula royleana. Ferreira et al. studied the responses of individuals of Xylopia aromatica to light intensity, regarding tree architecture and specific leaf areas in two savanna habitats. An anatomical study by Gama et al. reports data about ontogeny, histology and structure of glandular trichomes of a Bignonia species.
The present issue closes the first year of BRJB editing by Springer. For editorial board of BRJB, it has been a period of adaptation, with natural difficulties arising now and then, which have been overcome with the help of the personnel of Springer, from both Europe and local teams. We have tried to strengthen the steps toward increasingly wider internationalization, including in the Editorial Board colleagues from countries other than Brazil. With increasing frequency, experts from abroad have been invited to review papers submitted to BRJB.

With the vicinity of the end of 2013, I thank the cooperation of SBSP (Sociedade Botânica de São Paulo), as well as the input of all members of the Editorial Board of BRJB, Europe and local personnel of Springer, the authors-who distinguished us their submissions-and all reviewers, who dedicated part of their valuable time toward the improvement of the quality of the journal. To all of you, I wish Happy Holidays and Happy New Year, and that 2014 be a period granting us lots of rewarding accomplishments.

São Paulo, December 2014

Antonio Salatino

Editor-in-Chief 